\title{
Correlation of Motivation and Value Orientation of Project Managers
}

\author{
Róbert Modranský ${ }^{1 *}$, Daniel Lajčin ${ }^{2}$ \\ ${ }^{I}$ Faculty of Management, Prešov University in Prešov, Konštantínova 16, Prešov, Slovakia \\ ${ }^{2}$ DTI University, Sládkovičova 533/20, Dubnica nad Váhom, Slovakia
}

\begin{abstract}
The objective of this paper is to identify the relationship between the dimensions of performance motivation and value preferences of project managers in large companies. To examine the relationship, it was first necessary to find out what the value system of project managers is and what their motivational profile is. The research took the form of a questionnaire survey in large Czech companies, which belong to CZ-NACE C. Standardized questionnaires were used for data collection. The PVQ questionnaire was used to determine the value system and the LMI questionnaire was used to determine the motivational profile. Data were evaluated by using descriptive statistics and relationships were evaluated by using Person's correlation coefficient. Student's t-test was used to verify statistical significance. It was found that the analyzed values in the set of respondents are almost the same, all analyzed values are perceived by the respondents as significant. The most represented value among the respondents is benevolence and the least represented is tradition. We identified identical findings in the case of analysis of performance motivation. Of the four dimensions of motivation examined, the project managers addressed confidence in success to be the most important. A statistically significant relationship was found between commitment and power and success, between flexibility and stimulation, universalism and benevolence, between self-control and power, success, conformity and safety, and between confidence in success and power, success and stimulation.
\end{abstract}

\section{Keywords:}

LMI;

PVQ;

Theory of Motivation;

Typology of Values;

Relationships between Values and

Motivation.

Article History:

Received: 22 February 2021

Revised: $\quad 19$ May 2021

Accepted: 26 May 2021

Published: 01 June 2021

\section{1- Introduction}

These days, a person is important for the organization both as a source of labour and also as a creative being who brings new ideas and innovative solutions into the organization. If the organization employs the right people for their business, it is important that the organization values them, appreciates their work, and is able to keep them. Especially today, when the average fluctuation in the Czech Republic is $15 \%$ and a healthy fluctuation is considered to be between 5-7\%, as Halbrštát (2018) stated in his report [1]. One of the important factors that help employers in organizations is the art of motivation. We can teach employees something, but what a person can do is determined by a certain set of knowledge and skills that the manager can influence only partially. It is important how the manager motivates employees to use their potential, knowledge, skills and at the same time reduces employee turnover. This is possible if the manager knows the motivation of employees and knows what the individual needs, how intensely he demands it and where he is going.

*CONTACT: Robert_modransky@centrum.cz

DOI: http://dx.doi.org/10.28991/esj-2021-01282

(C) 2021 by the authors. Licensee ESJ, Italy. This is an open access article under the terms and conditions of the Creative Commons Attribution (CC-BY) license (https://creativecommons.org/licenses/by/4.0/). 
One of the sources of motivation are values, i.e. the value system of an individual. An individual during his life, experiences certain situations, encounters various phenomena that he evaluates, and thus creates a value system. That is why the values are subjective. Individuals often inherit values from their surroundings, and the value system often changes over the course of their lives. Values motivate human action because people direct their actions where it makes sense to them and has some value to them. People do not learn values, but create them themselves throughout their lives.

Values do not only relate to the work environment, work motivation, but values are related to a wide range of human life. It is important for organizations to know the value system of their employees, so that they can motivate them properly.

We focus on the job position of project manager. In the conditions of the Czech Republic, this is a relatively young job, where the project manager was included in the National System of Occupations only in 2014. However, hand in hand with dynamic development of project management, its implementation and application across companies of all sizes and different industries and project orientations especially for large companies, there is also the development of the use of the profession of project manager and the understanding of the perception of the content of this profession by the general public. The profession of project manager has so far been examined in the conditions of the Czech Republic only in terms of characteristics and competencies, a more detailed examination of the functions, roles or other attributes of human resource management has not been studied in the Czech Republic. So we identified the necessity to research deeply the profession of project manager, mostly in the context of the project team members motivation.

The project manager, whether in a junior or senior position, manages a project team of various sizes. The art of working with project team members can affect the overall synergy and dynamics of the team and thus ultimately the success of the project. One of the most important aspects of performing a job as a project manager is the art of motivating own team. Therefore, in the presented work we deal with the issue of motivation in the work environment and the value system of the individual, i.e. the junior and senior project manager, who is conditioned by the social environment.

The objective is to find out the value preferences of selected project managers and the degree of selected dimensions of motivation to perform. Based on the results, to analyze the relationship between the value preferences and dimensions of motivation. The result is whether motivations and values are in corellation.

It is important to realize that not only individuals have values, but values are also shared in organizations and employees should be identified with them so that work motivation can be even more successful. As we mentioned, the values of each individual are subjective, so the rewards at work are perceived differently for each individual.

\section{2- Problem Formulation and Methodology}

The objective of the research was to analyze the correlation between value preferences and dimensions of the motivational performance in a selected sample of senior and junior project managers. The partial objective was to find out what is the value system of the respondents and what is their motivational profile.

The objectives were defined based on the theoretical background. The relationship between values and motivation can be considered important for project managers for their managerial work. Project managers are not always aware of this potential connection, however, its impact on managerial work is significant, even if it is not aware. The values of project managers are reflected in the leadership of project team members, their motivation to work, while it is always desirable that the values of project managers are in correlation with the values of the organization. If the relationship between values and motivation proves as significant, the results of our research can help project managers to better understand themselves and to become aware of certain behavioural tendencies that may not always be desirable. Similarly, the findings of the research can be beneficial for HR professionals when recruiting new employees, if they are aware of the values that the organization seeks from its employees. The result can be increased by performance and prosperity of the organization.

Research questions are compiled in such a way that they correspond with the research objective. There are seven research questions formulated:

- What is the content of the value system of senior project managers?

- What is the content of the value system of junior project managers?

- What is the difference in the content of value system of senior project managers and junior project managers?

- What is the structure of the motivation dimensions of senior project managers?

- What is the structure of motivation dimensions of junior project managers?

- What is the difference in the structure of motivation dimensions of senior project managers and junior project managers?

- What is the correlation between the content of the value system and the dimensions of motivation in a research sample of analysed project managers? 
The research sample was selected from large organizations, which are defined by Srpová and Řehoř (2010) [2] as an organization with more than 250 employees, with an annual turnover of more than 50 million euros, or with assets of more than 43 million euros. Furthermore, the selection of the research sample was limited by the classification of economic activities CZ-NACE focused on category C, i.e. the manufacturing industry. Thanks to the research sample, which consists of large organizations, and according to the results of Hrazdilová Bočková (2005) [3] in the context of saturation of the manufacturing industry by project orientation, we were able to conduct research with senior and junior project managers. High demands are placed on project managers in large organizations, which corresponds to a higher financial reward. Large organizations expect high professionalism from their project managers, but different demands are placed on senior and junior project managers.

The research sample included 23 respondents, senior project managers, and 19 respondents, junior project managers. A standardized Portrait Values Questionnaire (PVQ) designed by Schwartz, was chosen to measure managers' values. We received the questionnaire from the publication by Řeháková (2006) [4]. The questionnaire was created due to the usability of the initial Schwartz Value Survey (SVS). Compared to this questionnaire, PVQ is shorter and easier to administer. As explained in Řeháková (2006) [4], the PVQ questionnaire is one of the questionnaires measuring values developed by Schwartz. In the original variant, respondents evaluated 57 specific values as leadership and management principles in an individual's life. The evaluation of this questionnaire is performed on a nine-point scale and the selected values measure the basic 10 value orientations, which according to the author are as follows:

- Power: social power, authority, wealth, having a good name, social recognition;

- Success: successfulness, ability, ambition, influence, intelligence;

- Indulgence: entertainment, enjoyment of life, intemperance;

- Stimulation: courage, colourful life, exciting life;

- Independence: curiosity, creativity, freedom, choice of one's own goals, independence, self-esteem;

- Universalism: environmental protection, relationship with nature, the world of beauty, tolerance, social justice, wisdom, equality, the world of peace, inner harmony,

- Benevolence: willingness, honesty, forgiveness, devotion, responsibility, spirituality, true friendship, emotional and spiritual intimacy, the meaning of life;

- Traditions: submission to the circumstances of life, piety, humility, respect for traditions, meekness, detachment from worldly interests;

- Conformism: obedience, respect to parents and the elderly, courtesy, self-control;

- Safety: cleanliness, national security, the return of services, social order, family safety, sense of belonging, health.

The same types of values are measured by the PVQ questionnaire, in which respondents do not evaluate specific values, but to them are presented short verbal portraits of 30 different people, where each of the portraits expresses one of the ten basic types of values. This questionnaire reduces the time-consuming nature of the SVS questionnaire, which also significantly claimed the cognitive abilities of the individual and it was not possible to use it with all persons, especially individuals with lower education or with less developed abstract thinking. The key is that the respondent cannot compare his own person with the portrait, but he should compare the presented portrait with himself - both approaches are different in the extent to which the individual is able to really focus on the observed values. If an individual was looking for the similarity between himself and the portrait, he would primarily focus on his own personality, the range of evaluated characteristics or traits would be much wider than one specific value expressed by the portrait, as a result of which the reflected value could be overlooked, or the individual would assume that he did not find a resemblance to his own personality in the portrait, which is not the purpose of the questionnaire.

When comparing the portrait with one's own personality, there is a greater concentration of attention on the presented value. The evaluation is made by choosing one of six options, which are "not at all like me", "very much unlike me", "rather unlike me", "rather like me", "very much like me" and "completely like me". The questionnaire takes approximately 10 minutes to complete and a 21-portrait version has also been developed, which takes approximately 56 minutes to complete [4]. As Mlčák and Záškodná (2015) [5] stated, values are expressed in desirable and leading objectives that motivate people to achieve them. Individual values can thus be grouped into motivational types, which express universal human needs and which therefore at the same time guide and motivate human behaviour.

To measure the motivational performance in research sample of junior and senior project managers was chosen the Performance Motivation Questionnaire (LMI), whose authors are Schuler and Prochaska (2011) [6].

According to Sedláková and Knapová (2017) [7], this questionnaire method should be applicable in all areas where performance efforts can be observed. Areas, where this method can be used the most, include sport psychology, school and career counselling, and personnel selection. The last-mentioned area is the most related to this research. The LMI questionnaire contains 17 dimensions, which are perseverance, dominance, commitment, confidence in success, 
flexibility, flow, fearlessness, internality, compensatory effort, pride in performance, willingness to learn, difficulty preferences, independence, self-control, orientation to status, competitiveness, sense of purpose. Each dimension contains 10 items, which are evaluated on a Likert scale of 1 to 7 . The evaluation is made by choosing one of seven options, which are "strongly disagree" to "strongly agree". It takes approximately 35 minutes to complete the questionnaire and the evaluation of the questionnaire is done by a simple sum of points. When creating the method, the authors initially identified 728 scales divided into 38 dimensions, which were gradually reduced to the final 17 dimensions with 10 items in each dimension.

Due to the time-consuming nature of the LMI questionnaire, which takes an average of 35 minutes to complete, and regarding the previous PVQ questionnaire, we selected 4 from the original 17 dimensions, which we consider to be the most essential for this work. When choosing these 4 dimensions, which are commitment, self-control, flexibility and confidence in success, we based on practice and we consider them as a key for the managers' work.

Commitment, as Schuler and Prochaska (2011) [6] pointed out in their research, represents an individual's willingness to give performance and to make some effort to do the job. People with high values work a lot, they like when their time is filled and do not feel good if they have nothing to do. They prefer work instead of other activities and do not need much time to rest in strenuous phases. In extreme cases, they may be referred as workaholics. These people are active, diligent, hardworking, ambitious and they are happy when they can work.

Self-control concerns the organization and performance of tasks. People with high values easily focus on the task and do not postpone their duties. What means, that they are disciplined and able to give up something to achieve long-term goals and the associated rewards. Typical features of self-control are planning, caution, thoroughness, conscientiousness and correctness [6].

Flexibility is the way how an individual copes with new situations and tasks. Individuals whose values are high interested and willing to learn new things are open to changes. They look for new stimuli and prefer situations in which they can learn something new. If they are flexible and look for new situations, they must also be prepared for the possible risk of failure that each new situation brings. These people are characterized by openness, adaptability, flexibility and interest [6].

The last dimension in the questionnaire is the confidence in success. Confidence in success represents the anticipation of the results of a particular behaviour that is successful. People with high values assume that they will achieve their goal even if they must perform new and difficult tasks. They do not allow themselves to lose and assume that they will successfully use their abilities even in the event of a fight against the competition. Typical features are planning, optimism, confidence, belief, self-confidence [6].

Each dimension contains 10 items, of which we selected 6, due to the time required to complete the questionnaire. The selected 6 items best describe the given dimension.

We evaluated the questionnaire for finding out value preferences to performance and the questionnaire for finding out motivational dimensions of respondents by using descriptive statistics.

In the PVQ questionnaire, respondents had a 6-point scale, with the lowest number 1, which represented the least similarity to a certain profile and the highest number 6 , which represented the greatest similarity. These profiles fit into 10 value orientations, so we created arithmetic mean for each value orientation to determine the average of the responses for each value.

We also used the same evaluation procedure, i.e., the use of the arithmetic mean in the LMI questionnaire. Respondents had 24 items for which they had to express their agreement/disagreement, to what extent the given statement corresponds to their person. They recorded the answers on a point scale from 1 to 7 , where 1 was a complete agreement and 7 a total disagreement. These 24 items in the LMI test fit into 4 dimensions, for which we created arithmetic mean and thus found the average of the answers for each dimension.

We used the results from the PVQ and LMI questionnaires to fulfil the main objective, i.e., to identify the correlation between value preferences and the dimensions of motivational performance. To verify the correlation between the dimensions of motivation and value preferences, we used the statistical tool Pearson's correlation coefficient, and we verified the statistical significance of the correlation by using Student's t-test, respectively p-value. 
Formulation of the research objective: to analyze the relationship between value preferences and dimensions of performance motivation in a selected sample of senior and junior project managers.

- The partial objective was to find out what is the value system of the respondents and what is their motivational profile.

Study of relevant research in the context of our research objective.

Formulation of research questions. 7 questions were formulated:

- What is the content of the value system of senior project managers?

- What is the content of the value system of junior project managers?

- What is the difference in the content of value systems of senior project managers and junior project managers?

- What is the structure of the motivation dimensions of senior project managers?

- What is the structure of motivation dimensions of junior project managers?

- What is the difference in the structure of motivation dimensions of senior project managers and junior project managers?

- What is the relationship between the content of the value system and the dimensions of motivation in a group of project managers?

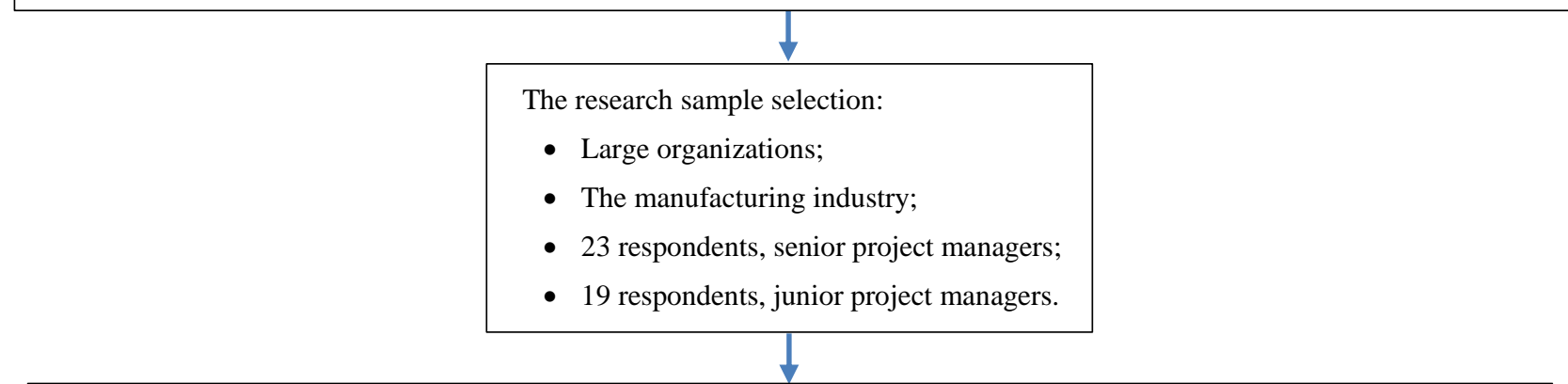

Research method identification:

- The standardized Portrait Values Questionnaire (PVQ) designed by S. H. Schwartz;

- The Performance Motivation Questionnaire (LMI), whose authors are H. Schuler and M. Prochaska, in a modified version with 4-dimensional analysis.

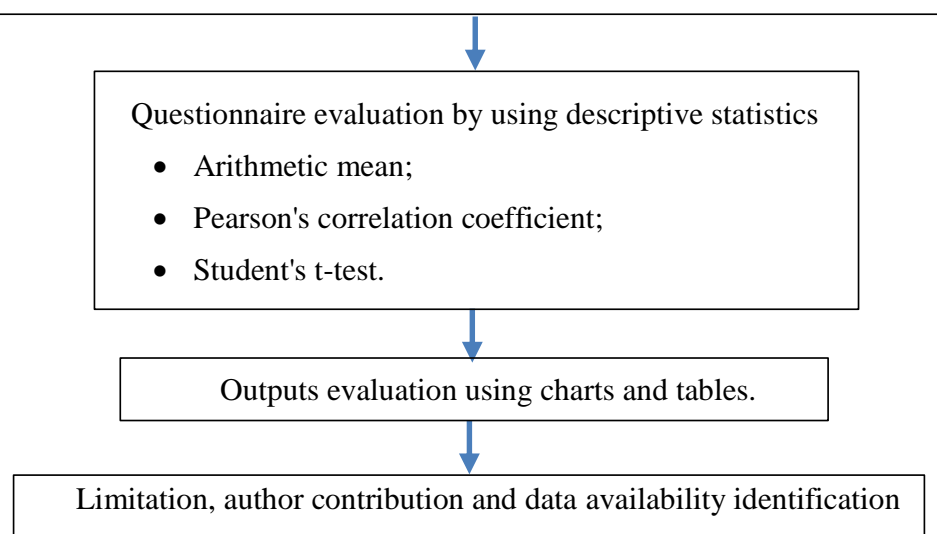

Figure 1. Research methodology scheme.

\section{3- Overview of the Current State of the Issue}

Both phenomena, i.e., motivation and values, are phenomena which are difficult to understand. Their definition depends on the theoretical basis of each of the researchers who is or has been working with them, for example Marsh et al. (2021), Tsai et al. (2021) or Youn et al. (2021), Henrich \& Muthukrishna (2021) and Vansteenkiste et al. (2007) [812]. Although even a layman can probably determine what motivation is or what is value, the scientific definition of these phenomena is not easy, and the agreement has not been found on how to view these phenomena yet. 
Values and motivation are closely related, especially with the use of the concept of functional autonomy of the motive, as it is stated by Lečbych and Seitl (2016) [13]. The author of the term is the American psychologist W. Allport, who came up with the theory that motives are created on the basis of needs, but their content is not deplented by them [14]. The new motive begins to work on its own, autonomously, even in situations where the original needs are already met, says Říčan (2009) or Weiner (2013) or Niermeyer and Seyffert (2011) [15-17].

The connection between values and motivation can be illustrated by using division of values into instrumental and terminal in M. Rokeache's work, for example Rokeach (1973 and 2008) [18, 19]. According to Ř́čan (2009) [15], terminal values are de facto motives. Instrumental values can be considered as means that serve to meet the basic needs of the individual. However, they become independent gradually, they form their own motivation, the instrumental value thus becomes a terminal value, which is already a motive for a certain action, say Lečbych and Seitl (2013) [20].

Rokeach (1973) [18] distinguished three components of values: the cognitive, affective and behavioral component. Cognition refers to knowing the desired, what the individual wants to go for. Emotions indicate an emotional relationship to the object to which the person is directed, the behavioral component is then closely linked to the plane of motivation, because the value becomes a source of human direction and action. However, other components are also motivating. As Prudký (2009) [21] summarizes, the inner values of the individual are governed by a person in his activities, relationships with others and are also important in terms of self-actualization.

Similarly, Schuster (2008) [22] refers to Rokeache's predecessor in examining the values of Spranger (1928) [23], Spranger (1928) conceived of values as goals, the goals which are lifelong. Personal values arise from the supraindividual value of unconsciousness, in which it is possible to distinguish six main values, resp. value orientations. We talk about theoretical, economic, aesthetic, social, political and religious orientations. These values are arranged hierarchically, like the motivation in the case of A. Maslow, where the lowest are theoretical and economic values. Values are reflected in behavior and through the behavior of an individual it is possible to know his value system.

Of course, the correlation between values and motivation can also be found in other theories, such as Triandis (1994), Hofstede (2011), and Inglehart (2000) [24-26]. As Výrost et al. (2019) or Quinn et al. (2020) [27, 28] explain, values permeate a person and are reflected in his behaviour and experience. Their source does not lie in the individual himself, but outside him - in the society of which he is a member. Education, individual experience and other social impacts have an influence. By internalizing values, motivation is released from direct dependence on specific activities and needs. Values thus lead to the direction of the individual, but the value is more than the value orientation.

According to the authors of the publication [27], it is true that "values are manifested in specific motivational similar value orientations, closely connected with needs and interests."

Values are closely correlated to needs, attitudes, goals, but the closest correlation is between values and motives, and to some extent, according to Lečbych and Seitl (2013) [20], values and motives can be considered as the same phenomenon, which is viewed from different perspectives. The values of the cognitive-affective system are emphasized, in the case of motivation, it is the energizing aspect. Lečbych and Seitl (2013) [20] tends to link values and motivation as formulated by Schwartz, where certain groups of values energize actions that are led in the same direction, thus creating a motivational type of values.

Seitl (2016) [13] further added that individual values lose their original meaning in the favour of the motivational type of values. The specific objectives of the negotiations represent the concretization of values. As Hemingway (2002) or Furnham et al. (2014) [29, 30] summarize, values and motivations, or rather motives, cannot be completely separated, the difference lies in which element is accentuated, i.e., whether it is an energizing effect, or whether cognitions and emotions become more important.

This correlation between values and motivation is or should be well known to managers and executives. It is difficult to motivate a worker to do something if his superior does not know what his values are. Knowledge of employee values is the key to increasing work productivity, employee devotion to the organization. Anything that an employee perceives as a value can become a source of motivation for the employee. Values thus stimulate a person's actions (of course not only in the field of work) and thus become an important element in the motivational structure of the individual. Effective management of the work process by the manager cannot take place without the thorough knowledge of the manager with the values of subordinates, the values of the organization are also important [31].

In principle, the manager must follow the values of the organization [32]. The subsequent aim is for employees to embrace these values and act on them. The manager requires subordinates to reflect these values in each of their actions (within the performance, concerning the manager). It is required that the values of the organization become the work motivation of subordinates [33].

Armstrong and Taylor (2015) [34] mentioned that this interconnectedness also explains why some managers' remuneration for work performed acts as a suitable motivation, others do not. Armstrong and Taylor (2015) [34] further add that it is the values of the individual that are gaining importance. A manager can motivate his subordinates if there 
is a clear and perceived relationship between performance or effort and the received reward, in terms of the value of this reward, which is so high that the individual decides to work in a certain way. Some workers may believe that material values are more important. In such a case, the motivational reward will be financial for them. However, the value system of employees is different and for each individual, the financial gain will not be an incentive, as finances will not be considered as a significant value for those concerned. Their own motivation may be preferred. However, the manager must be able to motivate every employee. The motivation will therefore vary for different employees, depending on their value system.

It is important to mention that even the managers themselves have their own value system. As reported by Nedelko et al. (2017) [35], what values the manager professes, influences his leadership style or management of employees of the organization. The authors of the book [35] conducted a study on a sample of Slovenian and Austrian managers, using Schwartz's questionnaire, and were also inspired by Hofstede's concept. Particular attention was paid to the value of power, less cultural differences were already identified. It was assumed that the leadership style of managers in the organizations of the two countries will be different: Austrian managers represent German culture, characterized by hierarchy, order, rules, etc. The authors rank Slovenia among the countries of Central Europe, where they perceive it as the preference for traditional solidarity, higher benevolence, fewer formalities.

It has been shown that managers from both countries have favoured an autocratic style that is linked to the very role of the manager, but this style has the form of a continuum. If the manager himself preferred values associated with power, his leadership style was more autocratic, regardless of the country or organization in which the manager worked. With the increase in traditional values or the influence of the values of a given culture on the organization, Slovenian managers tended to have a democratic leadership style, which did not apply to Austrian managers. External influence is so significant; however, values are internalized in the process of socialization and have a significant influence on human behaviour, stronger than the influence of the external environment. However, the cultural conditionality of values is also important, it affects the personal system of values, while according to the authors it is subsequently important what value it is. Culture can strengthen the value system of an individual in various contexts, it has a significant influence on the value orientation of a person. According to the authors of the book [34], if a management style is to take a certain form, it is necessary to develop this style, considering both the values of the manager and the values of the culture of which he is a part.

The authors of the presented article place motivation in connection with the resources that contribute to its formation and which include needs, habits, interests, ideals, but also values. Most of these phenomena are formed only during the life of an individual, so their determination by the process of socialization is considerable. Biological origin can also be considered, especially for needs. The final form of motivation is then a combination of all relevant factors, which are updated at a certain moment.

\section{4- Results and Discussion}

The first, second and third research questions concerned the content of the value system of senior and junior project managers in the analyzed companies. Bellow we present the found data graphically concerning values and added with an interpretation of the given finding.

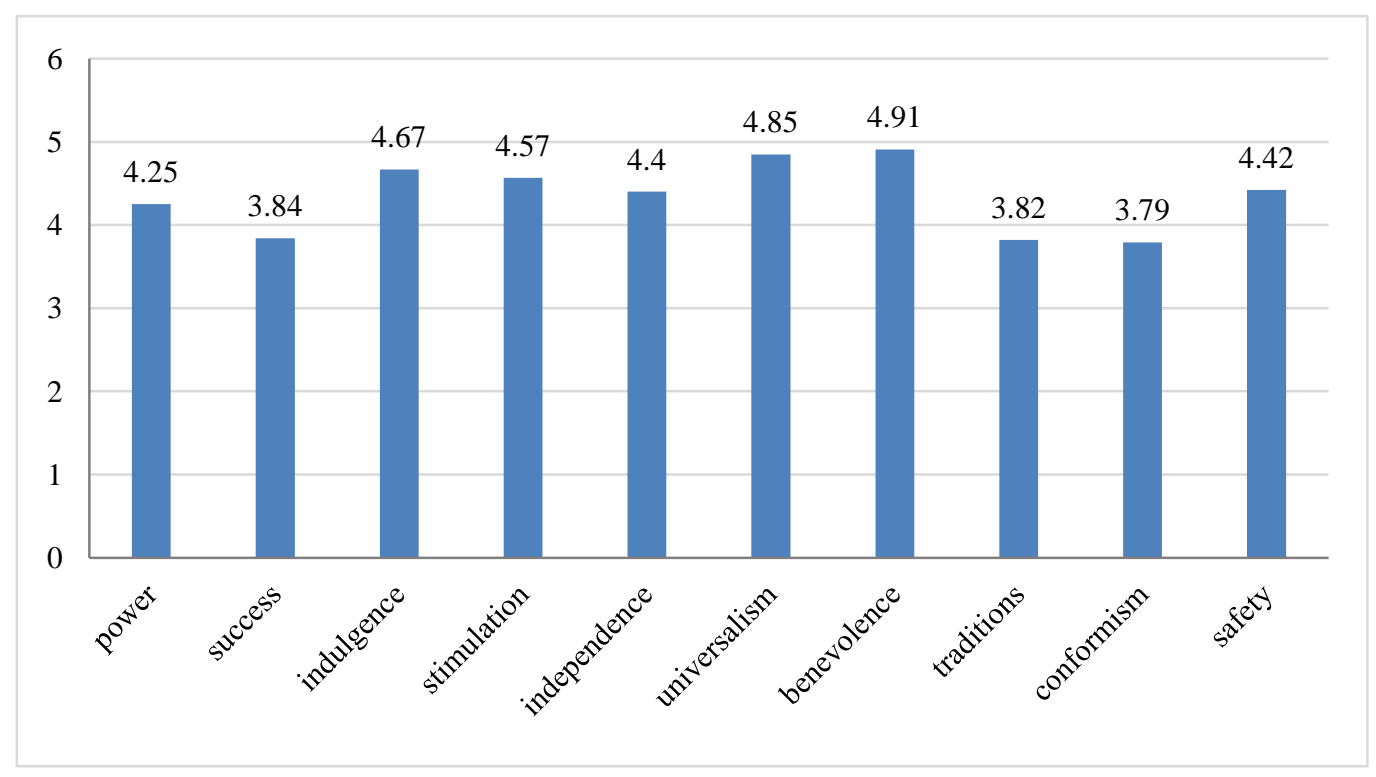

Figure 2. The average of the points of individual value orientations for the research sample. 


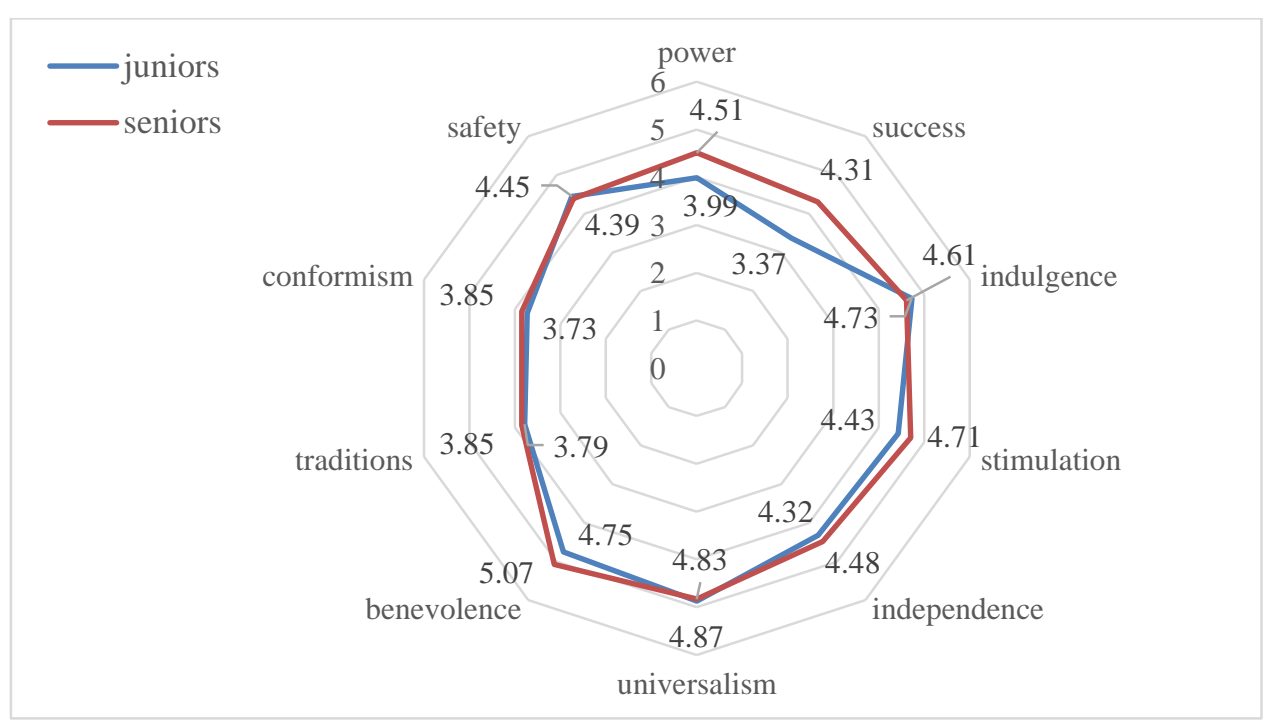

Figure 3. Results of value orientations for junior and senior project managers.

For both groups of respondents, the values of benevolence and universalism ranked first and second. These values have a positive designation. A manager who has these values high on his value scale is more benevolent and more tolerant of the opinions of others. He is responsive to the requirements of employees, he can appreciate them, even forgive mistakes and transgressions. Such the manager is a supporter of social justice, equality between people and is a supporter of the environmental protection. We consider these values to be crucial, especially today. We live in a tolerant society where individuals are not preferred, or vice versa oppressed minorities or individuals different from the general population. Similarly, nowadays, organizations that have the largest market share are not successful, or rather it is not the only criterion for success, but for today's customers it is much more important what organizations have social responsibility and what is their creation of economic values through social values. Therefore, if environmental protection is important for managers, it is one of the aspects of a quality manager today. It is important for HR professionals to realize what values managers profess to create the conditions for them to satisfy these values, and thus contribute to the well-being of the organization. Also, to know what to expect from managers, as values tend to manifest in behavior.

In both groups, success, tradition and conformism are in the three least scored positions, differing only in order. Despite the fact that these values are placed on the last three places, they are very highly scored, and therefore they cannot be neglected by managers at any level. We consider the values of success and conformism to be desirable for managers. We consider the only values that belong to the values of tradition, i.e. respect for tradition, humility, modesty and devotion, to be a slight disadvantage for managers. As we have already commented on this, managers in general have to come up with new, innovative ideas and be seen as an authority, and this value does not confirm much, on the contrary, it is in conflict.

However, even in this case, examples can be found where a manager with a strong emphasis on tradition will be important for the organization. The tradition includes, for example, humility, submission to life circumstances or detachment from worldly interests. It is necessary to emphasize that managers, together with organizations, go through developments that are largely determined by developments in society. In another way, the manager will act in the context of crisis management, in another way a manager whose task is to focus on future market developments to innovate in the organization, in an effort to ensure the organization's prosperity in future times. The organization does not always hire crisis managers when needed. The line of managers does not always change if the organization decides to change its goals. The manager must be flexible, i.e. he must be equipped with all the values important for the performance of his profession.

The importance of the values associated with the value of tradition can be seen at a time when society as a whole or the world is facing a crisis in connection with the Covid-19 pandemic. Not only do many organizations come up with innovations, but we can also see a significant adjustment to the organization of this event, which is reflected, among other things, in disregarding the goal of generating profits, in favor of helping the population, and at the expense of their own losses.

In the Schwartz model, there is a tradition alongside security (values such as national security, belonging, health, social order). These values give rise to second-order values, which in this case are conservation. Thus, some social events can put pressure on organizations (managers) and it is necessary for managers to be able to respond appropriately to this pressure, even in the context of the values that belong to society. After all, Schwartz also emphasized that values relate both to the behavior of individuals and to the behavior of larger communities, societies. These two planes certainly cannot be separated from each other, and there are situations where they intersect more. If the manager did not 
understand this mechanism sufficiently, if he did not have these values, he would not be able to respond to the needs of society, which significantly affect the operation of the organization.

Thus, it can be concluded that the representation of the value of tradition among managers may or may not be a disadvantage in the context of the content of the manager's work. The primary is to determine from the organization looking for a new manager what to expect from him. If it is to be a certain ferocity, flexibility, skill of innovation, it is certainly not appropriate to hire a manager in such a position, where tradition is strongly represented. However, in the non-profit sector, charitable aid, etc., it will be welcomed if the manager also has this value at his disposal. It can also be stated that this is one of the "traditional", basic human values, which we find, for example, in the Ten Commandments. Every individual, including the manager, should have humility and the ability to behave "humanly", especially in unexpected and crisis situations. From the point of view of the characteristics of the manager's profession, however, this value is usually not emphasized, although this area also changes, see e.g. emphasis on corporate social responsibility.

The fourth, fifth and sixth research questions determine the structure of the dimensions of motivation in senior project managers and junior project managers, where we proceed in the same way as in the presentation of data as in determining values.

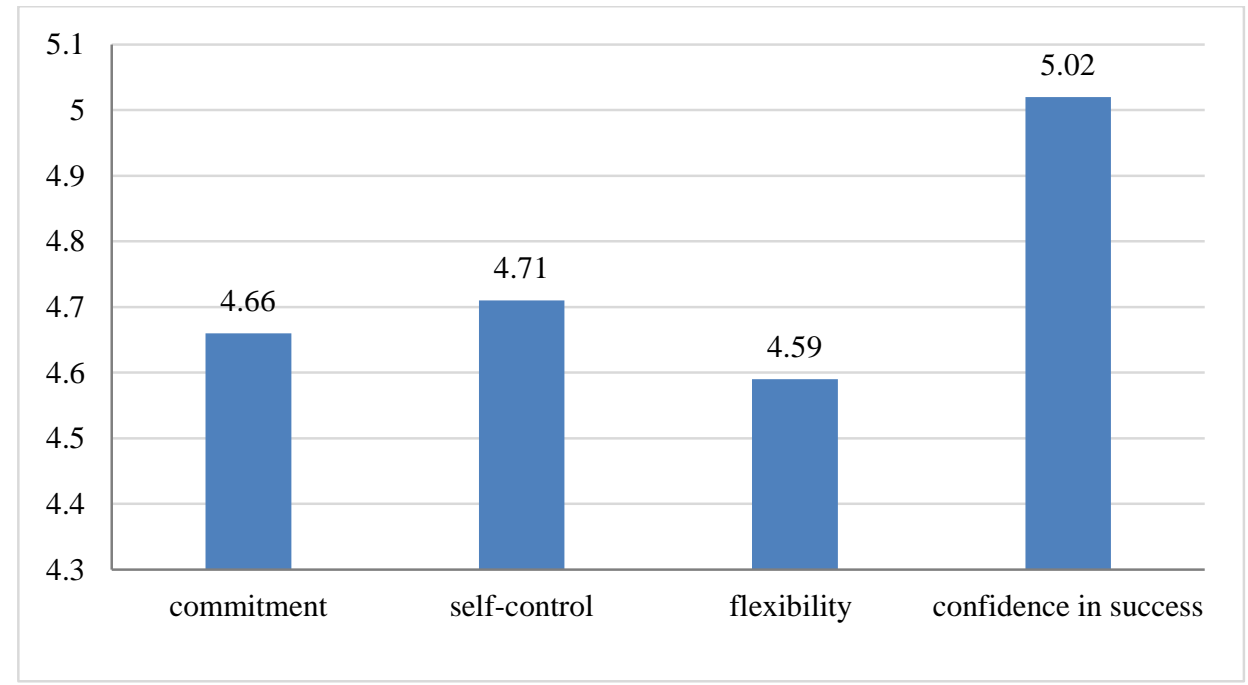

Figure 4. The average of the points of individual motivational elements for the research sample.

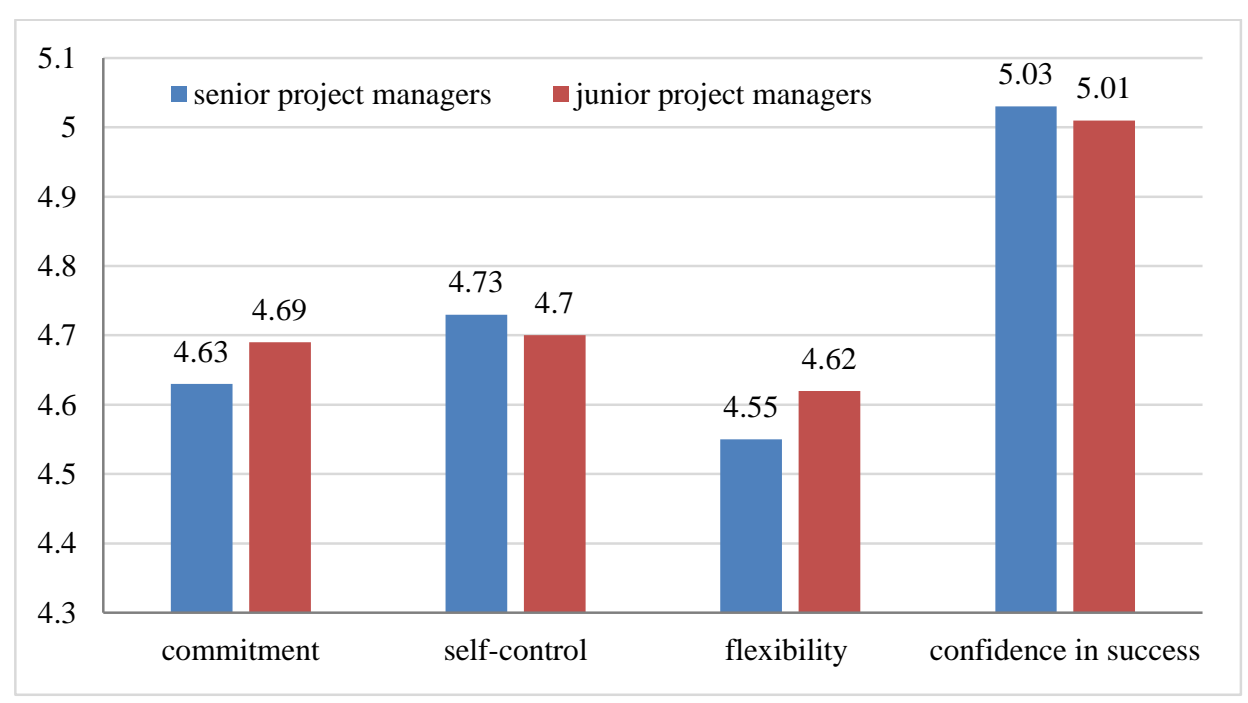

Figure 5. Results of motivational elements in senior and junior project managers.

Since the results of senior and junior project managers are almost identical, we generalize the following observations to the whole group of respondents, and therefore we proceed from Figure 4.

The figure shows that the motivational elements are strongly represented among the respondents and the motivational process should all be satisfied; they are important for the respondents. Confidence in success has reached the highest points, representing the assumption that individuals will succeed even when they overcome new challenges. This is due to the fact that individuals must be optimistic and should show signs of a certain healthy self-confidence. Respondents scored high on the PVQ values questionnaire and the LMI performance motivation questionnaire confirms Schuler and 
Prochaska (2011) claimed that people with high performance values also have high performance motivation. This can be seen by comparing Figure 2 with Figure 4.

The seventh research question aims to fulfil the primary objective of presented paper, finds out the correlation between the content of the value system and the dimensions of motivation in a group of project managers working in the manufacturing industry. Here are tables with Pearson's correlation coefficient, which presents the correlation between values and motivation. This correlation is presented in four tables, where each table expresses the correlation of one motivational dimension to values.

The results for the selected dimensions of motivation and their possible correlation with the values captured by the PVQ questionnaire are presented in Table 1, where the results for each of the selected dimensions of motivation are presented separately. The higher the correlation coefficient is, the stronger is the relationship between the two variables. Regarding the determination of a statistically significant relationship between the two variables, this correlation was found when the p-value was less than 0.05 . The tables highlight the most important correlations and statistically confirmed relationships between the selected dimension of motivation and specific values.

Table 1. Commitment and value preferences correlation.

\begin{tabular}{|c|c|c|c|c|c|c|c|c|c|c|}
\hline & 司 & 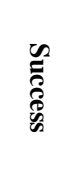 & 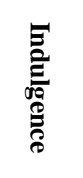 & 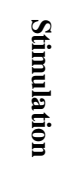 & 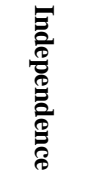 & 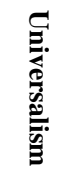 & 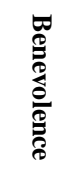 & 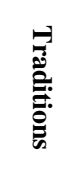 & 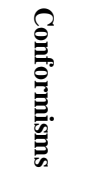 & 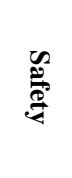 \\
\hline $\begin{array}{l}\text { The correlation } \\
\text { coefficient }\end{array}$ & 0.378 & 0.544 & 0.150 & 0.202 & 0.187 & 0.161 & 0.213 & 0.240 & 0.113 & 0.007 \\
\hline $\mathrm{p}$-value & 0.014 & 0.001 & 0.341 & 0.200 & 0.235 & 0.309 & 0.176 & 0.125 & 0.478 & 0.966 \\
\hline
\end{tabular}

Table 1 shows the correlation between commitment as a selected dimension of motivation and two values, which were power and success, for which the correlation was also statistically confirmed as significant.

This addiction is not surprising. If the manager is involved in his job role, success is important for him. The correlation with power can already accentuate the specific focus of the manager. Power contains values such as wealth, social recognition, maintaining a good reputation. Therefore, if the manager considers these values as important, it can be assumed that even from his role as a manager, which is associated with decision-making, influence, management, and leadership of human resources, he will strive to fulfil them in practice.

Of course, the obtained result does not determine what the consequence is and what is the cause in this case, but as stated in the theoretical background, values and motivation are related and these selected values (confirmed values) bring with them the need for some initiative, activity, and therefore commitment, which, moreover, is expected of managers. Table 2 shows the results for the motivational dimension, represented by flexibility.

Table 2. Flexibility and value preferences correlation.

\begin{tabular}{|c|c|c|c|c|c|c|c|c|c|c|}
\hline & Ð & 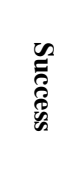 & 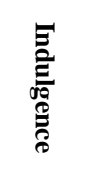 & 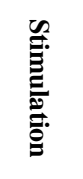 & 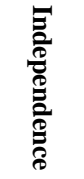 & 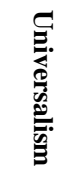 & 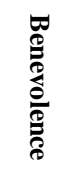 & 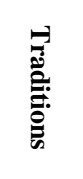 & 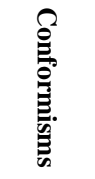 & $\begin{array}{l}\frac{\pi}{\vec{*}} \\
\frac{\mathscr{\theta}}{2}\end{array}$ \\
\hline $\begin{array}{l}\text { The correlation } \\
\text { coefficient }\end{array}$ & 0.296 & 0.277 & 0.175 & 0.554 & 0.301 & 0.450 & 0.345 & 0.213 & -0.085 & 0.214 \\
\hline $\mathrm{p}$-value & 0.057 & 0.076 & 0.269 & 0.001 & 0.053 & 0.003 & 0.025 & 0.175 & 0.594 & 0.173 \\
\hline
\end{tabular}

In Table 2 it can be seen that there is a moderately positive correlation between stimulation and universalism, a less strong correlation was found with indulgence, and a statistically significant correlation with flexibility was confirmed for all three values. Stimulation is connected to courage, an exciting life. Universalism refers to values that can be considered higher or basic human values. These include, for example, environmental protection, inner harmony, wisdom. Benevolence is about willingness, honesty, responsibility, the meaning of life.

It is obvious that all these values require from the individual openness to everything new, to the external environment, but to a large extent to their own internal factors (emotions, needs, etc.). Thus, it is possible to express assumptions that it is mainly valued, their specific content, that determines what the behaviour of an individual will be, given the focus of motivation. This motivation (i.e. flexibility) can thus become a way to update internally experienced and perceived values in their actions. Table 3 is related to self-control. 
Table 3. Self-control and value preferences correlation.

\begin{tabular}{|c|c|c|c|c|c|c|c|c|c|c|}
\hline & 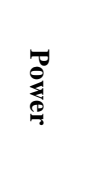 & $\begin{array}{l}\mathscr{\infty} \\
\tilde{\mathscr{\delta}} \\
\tilde{\mathscr{\delta}}\end{array}$ & 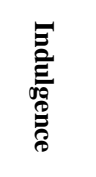 & 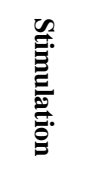 & 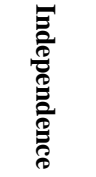 & 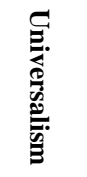 & 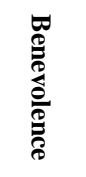 & 葛 & 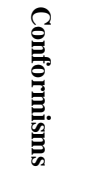 & 递 \\
\hline $\begin{array}{l}\text { The correlation } \\
\text { coefficient }\end{array}$ & 0.399 & 0.389 & -0.104 & -0.064 & -0.013 & 0.222 & 0.203 & 0.183 & 0.469 & 0.464 \\
\hline p-value & 0.009 & 0.011 & 0.511 & 0.689 & 0.934 & 0.158 & 0.197 & 0.246 & 0.002 & 0.002 \\
\hline
\end{tabular}

As can be seen from Table 3, a statistically significant correlation was found between self-control and power, success, conformity, and safety. This correlation was strongest in terms of conformity and safety.

Safety concerns social order, a sense of belonging, national security, family security. Conformity is associated with obedience, respect for parents, traditions, detachment from worldly interests. Self-control usually leads to such behavior, at the same time again it is true that the given values probably influence the focus of the individual's motivation.

The manager will hardly be able to give high performance and to manage the power entrusted to him if he does not have certain self-control. People with high self-control are unable to postpone their responsibilities, they are consistent in their actions, so this consistency can also be given by the values associated with it.

Table 4 shows the last correlation examined, linked to confidence in success. This table shows a strong correlation between confidence in success and success. Power and confidence in success are a moderately strong positive relationship, same as with stimulation. For all three values, a statistically significant correlation with confidence in success as a dimension of motivation was found. Confidence in success represents the expectation of positive results of a certain action. People who have this motivation tend to be optimistic about their chances of success in a particular area. Again, it should not be considered surprising that a correlation was found between this motivation and power, success, and stimulation (stimulation refers to courage and exciting life, without courage new things cannot be tried).

Cakirpaloglu (2012) [36] added that if one repeatedly experiences success, he is more confident that one can achieve this success by one's own efforts. People who believe in their ability, who are not afraid to try new things, who perceive a challenge in failure and try to change what can be achieved to achieve the set success, are called internalists. Conversely, people who attribute success or failure to chance, instead of their abilities, do not primarily believe in success. However, we do not find many people from the second group, the so-called externalists, among the managers, which was confirmed by our research.

Table 4. Confidence in success and value preferences correlation.

\begin{tabular}{|c|c|c|c|c|c|c|c|c|c|c|}
\hline & 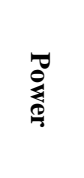 & 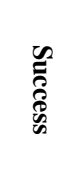 & 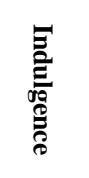 & 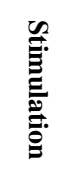 & 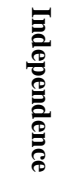 & 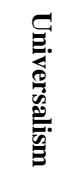 & 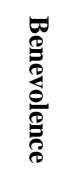 & 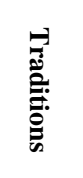 & 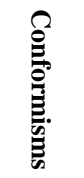 & 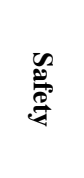 \\
\hline $\begin{array}{c}\text { The correlation } \\
\text { coefficient }\end{array}$ & 0.539 & 0.629 & 0.173 & 0.404 & 0.261 & 0.164 & 0.300 & 0.155 & 0.139 & 0.133 \\
\hline p-value & 0.001 & 0.008 & 0.273 & 0.009 & 0.095 & 0.299 & 0.054 & 0.328 & 0.378 & 0.402 \\
\hline
\end{tabular}

The values of selected dimensions of motivation (commitment, flexibility, self-control, and confidence in success) in the research sample of managers were related to the representation of values examined by the PVQ questionnaire, thus answering the seventh research question to determine the relationship between the value system and the dimensions of the motivation of project managers.

The results showed that the values of power and success intertwine with all selected motivational dimensions except flexibility. Not only did a correlation with success and power as values emerge between these dimensions of commitment, self-control, and confidence in success, but this correlation was also verified as statistically significant.

In the case of commitment, a statistically significant correlation with the value of power and performance was found. If commitment indicates a willingness of an individual to give high performance, to work hard, when work is one of the important values, a correlation to success can be understood.

When we talk about power, it is related to values such as authority, wealth, social recognition, which Řeháková claimed in (2006) [4]. Commitment can thus be a way of fulfilling these values. At the same time, power in Schwartz (2012) [37], also expresses control and dominance over resources, including human resources. 
Therefore, it is not surprising that a significant representation of power was found among the research sample of managers. Depending on the obtained results, it can also be argued that power and success as values professed by the manager are intricately linked to the motivation to commitment. If a manager strives for power and wants to deliver high performance, he can also be expected to be motivated to engage highly. Personnel should be aware of this fact, as will be emphasized in more detail in the recommendations for management and personnel.

Furthermore, a statistically significant correlation was demonstrated between flexibility as a dimension of motivation and stimulation, universalism and benevolence as values represented of managers. It can be added that the values of universalism and benevolence are related to second-order values, expressed as self-transcendence, as stated by Řeháková (2006) [4]. Again, this result is not surprising. Flexibility is correlated, among other things, to preparedness for the possible risk of failure that each new situation brings. These people are characterized by openness, adaptability, flexibility, and interest, as confirmed by Schuler and Prochaska (2011) [6].

It is therefore understandable that flexibility is associated with courage, a varied life (i.e. stimulation), tolerance as a value belonging to universalism and forgiveness or willingness as values representing forbearance. The three identified value preferences, related to flexibility, can also express a tendency to protect the environment, responsibility, i.e., values that are increasingly emphasized in today's society. It is therefore not about the flexibility that does not respect the rights of others. If these values and the given motivation are more represented in the manager, as it was found in the examined research sample of managers, it is a manager who should be sought after by organizations that pay attention to social responsibility and innovation.

The third examined dimension of motivation was self-control, in which a statistically significant relationship with the values of power, success, conformity and safety was found. The correlation between self-control, power and success are again understandable. As far as safety is concerned, in Schwartz's conception, it means national security, health, social order, conformity is about obedience, courtesy, respect for authorities. In this case, it can be stated that project managers characterized by higher self-control can be beneficial for the organization, as they can also be expected to have a certain loyalty to the management of the organization, its goals. Self-control is largely at odds with the flexibility mentioned above. The result confirms the capture of values on the motivational continuum, represented by the Schwartz circle, in which these values stand against each other (conformism and safety are in opposition to stimulation and independence, power and success are placed opposite the universalism and benevolence). The high representation of flexibility and self-control in the person of the manager thus makes such a manager an individual who can reflect both the needs and interests of the organization and the needs and interests of society. Less distinctiveness (i.e., lower level of given values) in the motivational and value focus of such a manager allows finding a correlation between the manager and the organization's management in the context of responses to change external conditions in which the organization finds itself.

Self-control has the strongest correlation with the value of conformity and safety, which belongs to the Conservation, i.e., the second-order category. Conservation is based on social aspects and at the same time self-defence against failure, threat. This raises the question of how this relationship can manifest itself in practice if self-control is reflected in the behaviour of managers and serves to achieve power and success (which also have a significant correlation with selfcontrol) but can also consider the social aspect of the second-order Conservation category. The correlation between these values and motivation can manifest itself differently in managers, on the one hand, it can be an effort not to deviate from the line or to provoke others with their behaviour. But it can also be an effort to be popular, successful among colleagues, which would develop good social relationships.

The last dimension of motivation examined was confidence in success. This motivation was found to have a statistically significant correlation with the values of power, success, and stimulation. It is good to look especially at the value of stimulation, which means courage, novelty, preference for new values in life. These are undoubtedly necessary conditions, i.e., necessarily present values, which should be represented by a manager who is expected to be optimistic, belief in change and its positive impact on the organization, so this type of managers will be welcomed in industries or organizations that focus on innovation.

The first research question was to find out what the content of the value system of senior project managers is. The research showed that the three most significant values out of 10, which are the focus of the PVQ questionnaire, include indulgence, universalism, and stimulation of senior project managers.

The second research question examined the content of the value system of junior project managers and the third research question found the difference in the content of the value system between senior and junior project managers. The two most important values for junior project managers were universalism and indulgence. So, these were relatively the same values as for senior project managers, apart from stimulation, which was represented by senior project managers, in junior project management this value was placed fifth. While indulgence was found in the case of junior project management in the third place in the set of 10 examined values, in the case of senior project management it was the fourth place. The differences found are therefore minimal. 
An attempt was made to find similar research to compare the results, but it was not possible to find studies that would determine the values of project managers through the PVQ or SVS questionnaire, which was created by Schwartz (2012) [37]. Only two found studies can be mentioned, namely Slovak research and Japanese research, which is, of course, older.

Samohýl (2012) [38] examined the representation of values according to Schwartz in 101 project managers. However, the author focused on the values of these managers depending on gender, where success, safety and indulgence were found to be the most frequently mentioned values for men, and around women were not find any differences. These values are therefore different from the values obtained in the described research.

Greater agreement can be found in research from Japan [39], which involved 45 managers from middle and top management. In this case, similar results were obtained as in our research, i.e., safety, independence, universalism, and indulgence). However, as Hoorn (2017) emphasizes, depending on the findings of his own research [40], people's values are significantly influenced by the culture in which people grow up, the society to which they belong. Thus, it cannot be assumed that all managers share the same values, nor is it true that within one society (nation) the values of the population or only a part of the population do not change depending on time, historical development.

The fourth research question was to find out what the structure of the dimensions of motivation of senior project managers is. The fifth research question followed the same, but with junior project management. The sixth research question found a difference in the structure of motivation dimensions of senior and junior project managers. In summary, almost identical results were obtained for both groups. Four dimensions of motivation were examined, namely commitment, flexibility, self-control, and confidence in success. Both groups were dominated by confidence in success, followed by flexibility, commitment and, the last one with the lowest, but still above average, self-control. The differences between the two groups were in the order of hundreds of points for all four dimensions of motivation.

These forms of motivational performance can be considered as especially important. The manager should be the one who believes in success and strives to achieve it, with his high commitment, which necessarily requires some selfcontrol, but also flexibility, because the manager is constantly facing various changes, crises. It can be positively evaluated that the representatives of senior and junior project management do not differ in this respect.

Values and motivation are closely related, which is confirmed by Rokeach (2008) [19]. They take on a motivational function, as a value orientation, they are linked to interests and needs, which is stated in Inglehart (2000) study [26].

The values of project managers are significant. They should be in correlation with the values of the organization, not only because the project manager's activities help to fulfil and promote these values, but they are intricately linked to the goals of the organization. However, the project manager is a role model for his subordinates, and it is very important that he has the values that are expected from employees of the organization, stated by Khelerová (2006) [33].

The research found a correlation between commitment and two values - power and success, between flexibility and three values (stimulation, universalism, and indulgence), between self-control and four values (power, success, conformity, and safety) and between confidence in success and three values (success, power, and stimulation).

It can be noted that some values (power, success, stimulation) are reflected in more motivational tendencies, but there is also a sense of interconnectedness in these dimensions. The flexibility in this respect is different, which requires the project manager to be open to change, the ability to bear the risk of failure. However, being equipped with all these dimensions of motivation, which are closely correlated specially to values such as power, success, stimulation, appear as a key aspects of project managers, resp. their significant characteristics.

Ježorská (2013) [31] emphasizes that the project manager should be aware of the connection between values and motivation. It is difficult to motivate members of project teams to do something if his superior does not know what his values are. Knowledge of employee values is the key to increasing work productivity, employee commitment to the organization. At the same time, according to the authors, anything that an employee perceives as a value can become a source of motivation for the employee. Effective management of the work process by the project manager cannot take place without a thorough acquaintance of the project manager with the values of subordinates, the values of the organization are also important.

The correlation between motivation and value orientation in managers were researched by Platow and Shave (1995), Masson and Otto (2021) or Golob et al. (2008) [41-43], partly in Heretik and Betáková (2011) [44], who bring very interesting and undoubtedly relevant results, however, these studies do not focus primarily on project managers, they are not prepared for the conditions of the Czech Republic and mainly use another tool research and research methodologies, which makes the results obtained incomparable with our results. However, they inspire further research in the context of the problem. 


\section{5- Conclusions}

Depending on the results obtained, it is possible to formulate recommendations for management and human resources, for greater clarity for each group of employees separately. However, it should be emphasized that the research was conceived as a pilot study, so the results cannot be generalized, even with regard to a small research sample. However, the obtained data indicate the suitability of further, follow-up research, also taking into account other variables (e.g. efficiency of the project manager's work, job satisfaction of subordinates, etc.). When proving the validity of the obtained data, the recommendations formulated bellow can then be considered suitable for implementation in practice.

As already mentioned, each organization should define what requirements it has for the project manager. In the selection process itself, it is then possible to focus on determining the values and motivational performance of candidates for the position of senior and junior project managers. The results also help HR professionals and others responsible for recruitment and selection processes to understand how to reach exactly the people the organization is looking for.

If a project manager is sought who is highly committed, it is necessary to focus on the values of power and success. In recruitment advertising or other forms of recruitment, it is possible to highlight the possibility of influencing events in the organization, considerable autonomy in human resource management, it is possible to address individuals who emphasize the degree of influence on events in the organization.

In the case of interest in a project manager, which should be primarily flexible (flexibility according to Schuler and Prochasky means interest and willingness to learn new things, openness to change, searching for new stimuli, prioritizing situations in which an individual can learn something new, it is appropriate to attract applicants, for example, the possibility of traveling, creating and leading own project teams, to focus on project managers who like change, is for attractive innovations in the organization. At the same time, however, it is possible to address representatives of today's generation $\mathrm{Z}$ or $\mathrm{Y}$, i.e. individuals who grew up in close proximity to modern technologies, like to use them, are at the beginning of various start-ups, profess corporate social responsibility, emphasize environmental protection, prevent discrimination and any social injustice. You can customize accordingly system of benefits, i.e. to offer work from home, use of various flexible working hours. For these managers it is necessary to focus on equal behavior, to perceive candidates as an equal partner who can bring a lot of new things to the organization, i.e. appreciate their efforts for change, initiative, ask in an interview about the possibility of changing the organization, be very interested in what these managers need from the organization to be willing invest your knowledge and competencies in it.

If an individual is sought who will be responsible, capable of long-term stable performance, even at the cost of delaying certain needs (i.e. a person with a high self-control), it is appropriate to highlight areas related to power, success, conformity and safety. This type of project manager can be used, for example, in various non-profit organizations that emphasize high performance, but at the same time pay attention to the promotion of important social values and social responsibility. It is possible to offer freedom in how the organization will profile itself towards the community of which it is a part, and individuals can be sought who are interested in improving the position of certain vulnerable groups in society. However, even in crisis management, for example, this type of project manager can be very successful.

The dimension of motivation called confidence in success is associated with the values of power, performance and stimulation. It is true that organizations should provide true information in their advertisements. An organization that is looking for a project manager with a high level of confidence in success (i.e., individuals who will be able and willing to invest a lot of time and effort to achieve the organization's goals) has a lot to offer, but only what it can actually accomplish. It also means adapting job requirements to the needs (values) of the workers themselves or potential candidates. It is necessary to offer the possibility of considerable autonomy, authority, gaining social prestige, but also great variability of working hours, use of various resources to achieve goals (possibility to hire co-workers at the discretion of the manager, use of modern technologies), willingness to listen to manager's ideas and implement proposed changes.

As for the project managers themselves, there is a need to appeal to an understanding of one's own values and motivations. Every manager should be aware of his strengths and weaknesses, he should strive to develop especially his strengths, which also correlate with the company's values. There may be partial discrepancies between an individual's motivation and his values, which may hinder the achievement of the maximum possible performance, efficiency, but also personal and professional development. Recognition of these specifics of personality can be helped by these tools, their combinations, however, only knowing own value system and focusing motivation does not mean the optimal translation in practice. Recognition of these characteristics of the manager's personality should only be the beginning of the work on oneself, which can be developed, for example, within coaching. However, it is certainly appropriate that the PVQ questionnaire in particular be a tool used by every manager - both for evaluating their own value system and for the possible recognition of subordinate values, in the case of top management the values of managers from lower levels of management. The manager himself should strive to understand all aspects of each of the 10 core values, because as the example of power has shown, in practice this power can take on different values - it can benefit the organization, society, but it can be abused by the manager for his own benefit. 
Every change begins from the moment of knowledge. If the manager repeatedly experiences failures in his role, it is appropriate to focus on the extent to which their values correlate with the values of the organization, what is the focus of his performance motivation. Based on such knowledge, it is then possible to more appropriately choose a future employer. However, as already emphasized, it is a valuable tool in the field of human resources management, which can be used whenever the manager faces conflict in the work team of subordinates, if subordinates do not deliver the required performance, do not act in accordance with about a very useful way to reduce turnover in an organization.

This recommendation contains an increased emphasis on knowledge of the values of subordinates on the part of managers and at the same time emphasizes that the manager himself must be aware of his value system and key motivations that significantly determine his behavior. If this is not the case, it is necessary to focus on this selfknowledge.

The research showed that the representation of values between the two sets of respondents is almost different, all 10 values are perceived by the respondents as significant. The most represented value among the respondents is benevolence and the least represented is tradition. Regarding motivation, even in this case differences were not found between the two groups of respondents. Of the four dimensions of motivation examined, the project managers addressed confidence in success as the most important.

When examining the possible dependance between 10 monitored values and 4 selected dimensions of motivation in the research sample, a statistically significant correlation was found between commitment and two values - power and success, as well as between flexibility and three values (stimulation, universalism and indulgence), self-control and four values (power, success, conformism and safety) and between confidence in success and the three values (power, success and stimulation).

It seems as very important to take into account the value and motivation of employees in personnel work as well as in the management of human resources, while managers themselves should understand the composition and dynamics of their value and motivation system very well.

The conducted research, conceived as a pilot study, can be an inspiration for other researchers, while the influence of other variables can be ascertained, such as the age of the manager or his role in the organization which the organization conducts business.

\section{5-1- Limitation}

The limit of the research is the low number of respondents. Studies examining the issue of motivation and values of managers in a similar way are almost not carried out. Based on the data presented above, concerning the size of the research sample and regarding its nature, the results cannot be generalized. Rather, the research has the character of a pilot study to verify the expected correlation between the value system and the dimensions of motivation, and to identify differences between senior and junior project managers in the value system and the dimensions of motivation.

As it was described above, the research used a standardized test for measuring PVQ values from the author S.H.Schwartz and a LMI questionnaire method for measuring motivational performance. If the correlation between value preferences and dimensions of motivation could be demonstrated in this work, it would be appropriate to extend research in this area to more organizations to use the results obtained in personnel work.

\section{6- Declarations}

\section{6-1-Author Contributions}

Conceptualization, R.M. and D.L.; methodology, R.M. and D.L.; formal analysis, R.M. and D.L.; writing—original draft preparation, R.M. and D.L.; writing-review and editing, R.M. and D.L. All authors have read and agreed to the published version of the manuscript.

\section{6-2-Data Availability Statement}

No new data were created or analyzed in this study. Data sharing is not applicable to this article.

\section{6-3- Funding}

Presented paper is one of the outputs of the project 1/0021/ Identification of Factors Motivating Certified Project Managers to Perform during COVID 19 Pandemic Home Office supported by VEGA, Slovakia.

\section{6-4- Conflicts of Interest}

The authors declare that there is no conflict of interests regarding the publication of this manuscript. In addition, the ethical issues, including plagiarism, informed consent, misconduct, data fabrication and/or falsification, double publication and/or submission, and redundancies have been completely observed by the authors. 


\section{7- References}

[1] Halbrštát, Jiří, High turnover multiplies the problems of companies with a shortage of employees. It pays mainly to pay attention to newcomers. "Logistics" (2018). Available online: https://logistika.ihned.cz/c1-66167040-vysokafluktuace-nasobiproblemyfirem-s-nedostatkem-zamestnancu-vyplati-se-hlavnevenovat-novackum (accessed on January 2021).

[2] Srpová, J., and V. Řehoř. "Basics of business (theoretical knowledge, examples and experiences of Czech entrepreneurs." Praha: GRADA Publishing (2010).

[3] Hrazdilová Bočková, Kateřina. "Project Management: Survival Strategy or Chimera? 1st part." "IT Systems”. 7(1-2). (2005).

[4] Řeháková, Blanka, "Measurement of value orientations by the method of value portraits by S. H. Schwartz." Sociological Review 42 no.1. (2006): 107-128. doi:10.13060/00380288.2006.42.1.07.

[5] Mlčák, Zdeněk, and Helena Záškodná. "K některým výsledkům výzkumu osobnosti dobrovolníků On some results of personality volunteers research." Psychologické Aspekty Pomáhání 2014 (2015): 61.

[6] Schuler, Heinz and Michael Prochaska. "LMI - Performance Motivation Questionnaire”. Test Center, Prague (2011).

[7] Sedláková, Jitka, and Lenka Knapová. “Dotazník Motivace k Výkonu: Recenze Metody.” TESTFÓRUM 5, no. 8 (March 30, 2017): 19-24. doi:10.5817/tf2017-8-132.

[8] Marsh, Herbert W., Kate M Xu, Philip D Parker, Kit-Tai Hau, Reinhard Pekrun, Andrew Elliot, Jiesi Guo, Theresa Dicke, and Geetanjali Basarkod. "Moderation of the Big-Fish-Little-Pond Effect: Juxtaposition of Evolutionary (Darwinian-Economic) and Achievement Motivation Theory Predictions Based on a Delphi Approach.” Educational Psychology Review (February 8, 2021): 1-26. doi:10.1007/s10648-020-09583-5.

[9] Tsai, Tsai-Hsuan, Yung-Sheng Chang, Hsien-Tsung Chang, and Yu-Wen Lin. "Running on a Social Exercise Platform: Applying Self-Determination Theory to Increase Motivation to Participate in a Sporting Event." Computers in Human Behavior 114 (January 2021): 106523. doi:10.1016/j.chb.2020.106523.

[10] Youn, Song-yi, Jung Eun Lee, and Jung Ha-Brookshire. "Fashion Consumers' Channel Switching Behavior during the COVID19: Protection Motivation Theory in the Extended Planned Behavior Framework." Clothing and Textiles Research Journal 39, no. 2 (January 28, 2021): 139-156. doi:10.1177/0887302x20986521.

[11] Henrich, Joseph, and Michael Muthukrishna. "The Origins and Psychology of Human Cooperation." Annual Review of Psychology 72, no. 1 (January 4, 2021): 207-240. doi:10.1146/annurev-psych-081920-042106.

[12] Vansteenkiste, Maarten, Bart Neyrinck, Christopher P. Niemiec, Bart Soenens, Hans Witte, and Anja Broeck. "On the Relations Among Work Value Orientations, Psychological Need Satisfaction and Job Outcomes: A Self-Determination Theory Approach.” Journal of Occupational and Organizational Psychology 80, no. 2 (June 2007): 251-277. doi:10.1348/096317906x111024.

[13] Seitl, Martin. “Test psychodiagnostic methods for employee selection”. Palacky University in Olomouc (2016).

[14] Allport, Gordon W. "Motivation in Personality: Reply to Mr. Bertocci.” Psychological Review 47, no. 6 (1940): $533-554$. doi:10.1037/h0059220.

[15] Říčan, Pavel. "Personality Psychology: The Field in Motion". Prague: Grada. (2009).

[16] Weiner, Bernard. "Human Motivation” Psychology Press, (June 17, 2013). doi:10.4324/9780203772218.

[17] Niermeyer, Rainer, and Manuel Seyffert. "Motivation”. Vol. 227. Haufe-Lexware. (2011).

[18] Rokeach, Milton. “The nature of human values”. Free Press. (1973).

[19] Rokeach, Milton. “Understanding human values”. Simon and Schuster (2008).

[20] Lečbych, Martin, and Martin Seitl. "The Association between Self-Report Attachment Dimensions and the Rorschach Oral Dependency Scale in a Sample of Czech Adults.” Rorschachiana 34, no. 2 (January 2013): 137-155. doi:10.1027/11925604/a000046.

[21] Prudký, Libor. “Inventura hodnot: výsledky sociologických výzkumů hodnot ve společnosti České republiky.” Praha: Academia. (2009).

[22] Schuster, Nikoleta. "The construct of "value" in psychological understanding." Czechoslovak Psychology 52, no.3, (2008): 265275.

[23] Spranger, Eduard. "Types of men. The psychology and ethics of personality." (1928).

[24] Triandis, Harry Charalambos. "Culture and social behavior." (1994).

[25] Hofstede, Geert. "Dimensionalizing cultures: The Hofstede model in context." Online readings in psychology and culture 2, no. 1 (2011): 2307-0919.

[26] Inglehart, Ronald. "Globalization and Postmodern Values." The Washington Quarterly 23, no. 1 (March 2000): 215-228. doi:10.1162/016366000560665. 
[27] Výrost, Jozef, Ivan Slaměník and Eva Sollárová. “Social Psychology: Theory, Methods, Applications.” Prague: Grada. Psyché. (2019).

[28] Quinn, Robert E., Lynda S. St Clair, Sue R. Faerman, Michael P. Thompson, and Michael R. McGrath. "Becoming a master manager: A competing values approach.” John Wiley \& Sons, (2020).

[29] Hemingway, Christine A. "An exploratory analysis of corporate social responsibility: definitions, motives and values." University of Hull, The Business School, (2002).

[30] Furnham, Adrian, Gillian Hyde, and Geoff Trickey. "The Dark Side of Career Preference: Dark Side Traits, Motives, and Values.” Journal of Applied Social Psychology 44, no. 2 (January 10, 2014): 106-114. doi:10.1111/jasp.12205.

[31] Ježorská, Šárka. "Review of the Book Motivation of Nurses and Job Satisfaction in Healthcare.” Profese Online 6, no. 2 (October 1, 2013): 41-42. doi:10.5507/pol.2013.019.

[32] Husted, Emil. “'Some Have Ideologies, We Have Values': The Relationship Between Organizational Values and Commitment in a Political Party." Culture and Organization 26, no. 3 (September 6, 2018): 175-195. doi:10.1080/14759551.2018.1518325.

[33] Khelerová, Vladimíra. "Communication and business skills of a manager." Prague: Grada. (2006).

[34] Armstrong, Michael, and Stephen Taylor. "Human Resource Management. Modern Concepts and Procedures." Prague: Grada (2015): 928.

[35] Nedelko, Zlatko, Tyler R. Morgan, and Vojko Potocan. "How power values influence on leadership style: A comparison of Austria and Slovenia." Economic and Social Development: Book of Proceedings (2017): 704-712.

[36] Cakirpaloglu, Panajotis. "Introduction to personality psychology.” Prague: Grada. (2012).

[37] Schwartz, Shalom H. "An overview of the Schwartz theory of basic values." Online readings in Psychology and Culture 2, no. 1 (2012): 2307-0919.

[38]Samohýl, Martin. "Preferred values in the relationship with the manager" (2012). Available online: https://is.ambis.cz/th/mm83g/Preferovane_hodnoty_v_partnerskom_vztahu_u_managera.pdf (accessed on January 2021).

[39] Giacomino, Don E., Michael D. Akers, and Atsushi Fujita. "Personal values of Japanese business managers.” In Business Forum. (1999).

[40] Van Hoorn, André. "Generational Shifts in Managerial Values and the Coming of a Unified Business Culture: A Cross-National Analysis Using European Social Survey Data.” Journal of Business Ethics 155, no. 2 (March 14, 2017): $547-566$. doi:10.1007/s10551-017-3488-4.

[41] Platow, Michael J., and Roger Shave. "Social Value Orientations and the Expression of Achievement Motivation." The Journal of Social Psychology 135, no. 1 (February 1995): 71-81. doi:10.1080/00224545.1995.9711404.

[42] Masson, Torsten, and Siegmar Otto. "Explaining the Difference between the Predictive Power of Value Orientations and SelfDetermined Motivation for Proenvironmental Behavior.” Journal of Environmental Psychology 73 (February 2021): 101555. doi:10.1016/j.jenvp.2021.101555.

[43] Golob, Urša, Marko Lah, and Zlatko Jančič. "Value Orientations and Consumer Expectations of Corporate Social Responsibility.” Journal of Marketing Communications 14, no. 2 (April 2008): 83-96. doi:10.1080/13527260701856525.

[44] Heretik, Anton and Janka Betáková. "PPP and psychological aspects management of marketing communications. "IT Tools in Knowledge Management in Organizations: Selected Problems." Czestochowa University of Technology, (2011): 92-96. 